\section{BRAZIULIAN JOURNAL}

OF MEDICAL AND BIOLOGICAL RESFARCH

www.bjournal.com.br
ISSN 0100-879X

Volume 43 (02) 124-225 February 2010

BIOMEDICAL SCIENCES

AND

CLINICAL INVESTIGATION

Braz J Med Biol Res, February 2010, Volume 43(2) 206-210

An improved in vivo method for atrioventricular node ablation via thoracotomy

R.H. Maclver, R.D. Stewart, C.L. Backer, S. Tsao, D.A. Harrington and C. Mavroudis

The Brazilian Journal of Medical and Biological Research is partially financed by
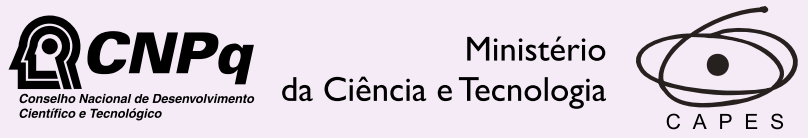

Ministério da Educação

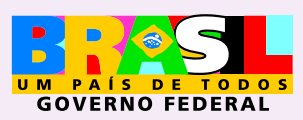

Institutional Sponsors

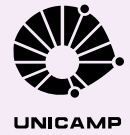




\title{
An improved in vivo method for atrioventricular node ablation via thoracotomy
}

\author{
R.H. Maclver ${ }^{1}$, R.D. Stewart ${ }^{1}$, C.L. Backer ${ }^{1}$, S. Tsao $^{2}$, D.A. Harrington ${ }^{1,3}$ \\ and C. Mavroudis ${ }^{1,4}$ \\ ${ }^{1}$ Division of Cardiovascular-Thoracic Surgery, ${ }^{2}$ Division of Cardiology, Children's Memorial Hospital, \\ Northwestern University Feinberg School of Medicine, Chicago, IL, USA \\ ${ }^{3}$ Institute for BioNanotechnology in Medicine (IBNAM), Northwestern University, Chicago, IL, USA \\ ${ }^{4}$ Current affiliation: Center for Congenital Heart Surgery, Cleveland Clinic Foundation, Cleveland, OH, USA
}

\begin{abstract}
The atrioventricular (AV) node is permanently damaged in approximately $3 \%$ of congenital heart surgery operations, requiring implantation of a permanent pacemaker. Improvements in pacemaker design and in alternative treatment modalities require an effective in vivo model of complete heart block $(\mathrm{CHB})$ before testing can be performed in humans. Such a model should enable accurate, reliable, and detectable induction of the surgical pathology. Through our laboratory's efforts in developing a tissue engineering therapy for $\mathrm{CHB}$, we describe here an improved in vivo model for inducing chronic AV block. The method employs a right thoracotomy in the adult rabbit, from which the right atrial appendage may be retracted to expose an access channel for the AV node. A novel injection device was designed, which both physically restricts needle depth and provides electrical information via electrocardiogram interface. This combination of features provides real-time guidance to the researcher for confirming contact with the AV node, and documents its ablation upon formalin injection. While all animals tested could be induced to acute AV block, those with ECG guidance were more likely to maintain chronic heart block $>12 \mathrm{~h}$. Our model enables the researcher to reproduce both $\mathrm{CHB}$ and the associated peripheral fibrosis that would be present in an open congenital heart surgery, and which would inevitably impact the design and utility of a tissue engineered AV node replacement.
\end{abstract}

Key words: Atrioventricular node; Heart block; Ablation; Tissue engineering; Regenerative medicine; In vivo model

\section{Introduction}

The atrioventricular (AV) node is an integral component of the cardiac conduction system, acting as both a relay station and a temporary pause for the pacing signal from the sinoatrial node. Its delicate position within the floor of the right atrium makes the AV node an inadvertent casualty of reconstructive procedures, with permanent damage in approximately $3 \%$ of congenital heart surgery operations (1). Currently, the only treatment for Class III AV heart block is the implantation of a permanent artificial pacemaker. While such devices have revolutionized patient survival and quality of life, their use implies a number of associated issues, including limited device lifetime, active patient awareness in strong magnetic fields, gradual reduction in lead conductivity due to wear or scar formation on the electrode, and, for the pediatric population, the inability of an artificial device to grow with the child. Future treatments, such as tissue-engineered biodegradable scaffolds, could successfully address these issues, through biointegration into the existing tissue (2).
Researchers in pacemaker design and alternative treatment modalities require an effective in vivo model of AV heart block before testing can be performed in humans. Multiple methods of $\mathrm{AV}$ node ablation have been described in the literature (3), including electrical, cryo, and chemical ablation, and/or cutting the AV nodal tract. The first use of a chemical sclerosing agent without an atriotomy to destroy the AV node was reported by Erlanger and Blackman in 1909 (4). They injected a mixture of iodine and alcohol directly into the area of the AV node, with poor results regarding the achievement of complete heart block (CHB). The technique was modified with improved results by changing to $10 \%$ formalin (5) and by using a bipolar mapping/injection device (6). Williams and Lambert (7) subsequently described a technique of creating AV block without the need of a thoracotomy by using a catheter guided by pressure, fluoroscopy and ECG to locate the AV node. Many studies use this catheter-based approach as it is less stressful for

Correspondence: C.L. Backer, Children's Memorial Research Center, Division of Cardiovascular-Thoracic Surgery, 2300 Children's Plaza, Chicago, IL, USA. E-mail: cbacker@childrensmemorial.org

Received March 4, 2009. Accepted October 20, 2009. Available online January 15, 2010. Published February 1, 2010. 
the animal, achieves excellent AV node targeting, and allows for immediate physiologic testing rather than having to wait for the animal to recover from a thoracotomy.

\section{Material and Methods}

For our own experiments, we deliberately chose to perform a thoracotomy followed by chemical injection into the AV node, since we feel that it most closely matches the conditions present in the pathologic state of AV block after cardiac surgery. Induction of AV block via a catheter would not create the peripheral adhesions and scar present after the pericardium has been opened in a thoracotomy. This is relevant when testing a potential implanted therapy, since functional integration of the graft will be significantly affected by the surrounding scar tissue. Using a thoracotomy also avoids much of the cost and setup of the catheter approach.

We chose to conduct our experiments in the adult rabbit, as it provides greater surgical access than the rat, but with reduced cost compared to the dog, sheep or pig. Notably, the catheter ablation method would also be difficult in this species, since much of the conventional equipment available is suitable for human and large animal use only.

While these points address the practical surgical aspects of the model, the success of the method relies primarily on the researcher's ability to obtain direct and accurate access to the AV node, to reliably deliver small volumes of the necrosis agent, and to definitively confirm ablation of the AV node tissue. To this end, we employed a 27-gauge needle, bent at $90^{\circ}, 5 \mathrm{~mm}$ from the tip, for injection (Figure 1A). This technique maintains a constant depth (as previously applied in other species $(8,9)$ but yet to be described in the adult rabbit) for insuring delivery to a defined location. Our initial feasibility experiments employed needles with shorter $(3 \mathrm{~mm})$ insertion lengths or alternate delivery angles $\left(0^{\circ}, 45^{\circ}\right)$; however, we found that the above parameters of $5 \mathrm{~mm}$ and $90^{\circ}$ were optimal for accessing the atrial groove and preventing an overestimation of the AV node location.

While the needle adaptation provided a physical guide to locating the proper injection site, we also sought a physiological confirmation. For this purpose, one end of a copper lead was secured to the needle's base, and the other end was connected to an ECG. Upon insertion of the needle into the atrial groove and contact with the AV node, an $\mathrm{H}$ wave formed on the ECG. This guidance was employed in every ablation procedure prior to injection. Without this electrical confirmation, multiple injections were often necessary for the initial induction of $\mathrm{CHB}$; $\mathrm{H}$ wave confirmation substantially reduced this need.

A final relevant parameter was the choice of a necrosis agent. Previous reports in rabbits and other species had indicated successful induction of $\mathrm{CHB}$ through the use of 70 or $100 \%$ isopropyl alcohol. In contrast to these reports, we obtained poor results using these agents in our early feasibility studies, and thereafter chose $10 \%$ neutral buffered formalin (NBF) as the injectate. NBF is readily available in many laboratories, and is known to induce fast and complete cell death. NBF was employed in all trials reported in this Communication.

With these parameters in place, we conducted a full set of experiments to confirm the method in adult New Zealand rabbits. After internal Institutional Animal Care and Use Committee approval (Children's Memorial Research Center), the 8 female rabbits (average weight $3.7 \pm 0.27 \mathrm{~kg}$ ) were anesthetized with $0.5 \mathrm{mg} / \mathrm{kg}$ acepromazine (Promace ${ }^{\circledR}$, Fort Dodge Animal Health, USA), $40 \mathrm{mg} / \mathrm{kg}$ ketamine (Vetalar ${ }^{\circledR}$, Fort Dodge Animal Health) and $7 \mathrm{mg} / \mathrm{kg}$ xylazine (Rompun ${ }^{\circledR}$, Bayer Healthcare, LLC, USA) before being intubated and placed on a ventilator with $2 \%$ isoflurane (Abbott Laboratories, USA), $1 \mathrm{~L} / \mathrm{min}$. Each animal was placed supine and tilted to the left $30^{\circ}$ with the right front leg extended upwards. The area of interest was shaved and swabbed thoroughly with betadine. The chest was accessed through a right thoracotomy approximately $4 \mathrm{~cm}$ in length at the fifth intercostal space. A subcutaneous pocket extending posteriorly $\sim 2 \times 2$ $\mathrm{cm}$ was made to house a Medtronic VVI pacemaker generator (MicroMinex $8360^{\circledR}$, Medtronic, USA). The lung was retracted with a $4 \times 4$ moist gauze. Avoiding the phrenic nerve, the pericardium was entered and retracted with 6-0 Prolene sutures to the chest wall creating a well. An epicardial lead was then secured to the surface of the right ventricle with two 6-0 Prolene sutures. The other end of the pacemaker lead was pulled through a 1-mm hole in the sixth intercostal space and threaded into the subcutaneous pocket.

The right atrial appendage was retracted to expose the area of the AV node for injection. The AV node's location was approximated by inserting the tip of the modified needle into the groove between the aorta and right atrium and directing the tip towards the septal cusp of the tricuspid valve. The location was confirmed by the identification of an $\mathrm{H}$ wave, using the needle-ECG lead described above. Injections of $10 \%$ NBF were made in 0.1-cc volumes until AV block was noted visually by continued atrial contraction with no subsequent coordinated ventricular contraction. Once successfully prepared, the animal was immediately paced at $180 \mathrm{bpm}$, first by the 2090 CareLink ${ }^{\circledR}$ Programmer (Medtronic), and then by the implanted pacemaker, with thresholds set at twice the rate of capture. Animals were monitored for AV node function postoperatively by reducing the rate of the pacemaker below the set rate of $180 \mathrm{bpm}$. Animals whose heart rates fell below $180 \mathrm{bpm}$ were determined to be in AV block.

After observing $\mathrm{CHB}$ and initiating external pacing, we waited 30 min to insure that permanent AV node ablation was obtained. Inadvertent recovery of the AV node due to incomplete ablation has been described (3), and this same issue was noted in our preliminary experiments. We observed empirically that $\mathrm{AV}$ ablation would be retained for the short term if function did not return within $30 \mathrm{~min}$, and we used this value to guide us in the full set of experiments. Upon 


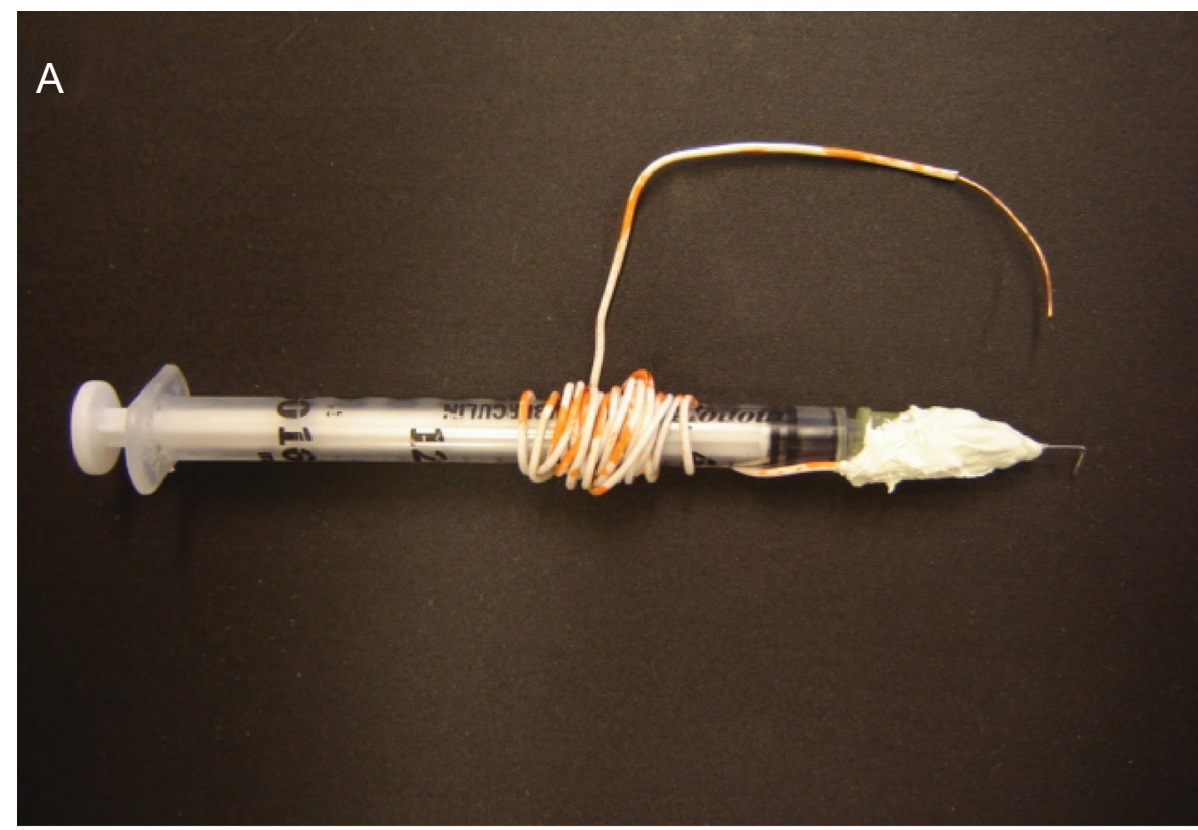

B

$25.0 \mathrm{~m}$

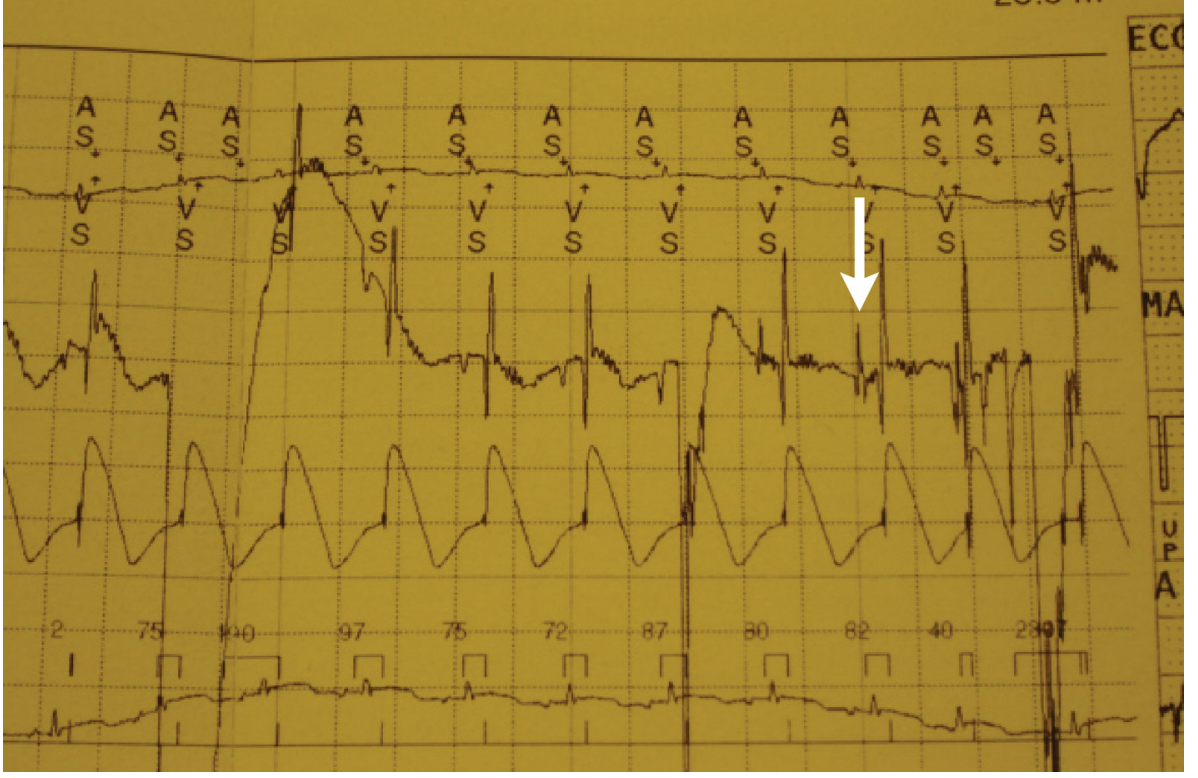

Figure 1. $A$, Modified injector with $90^{\circ}$ bent tip, 5 -mm injection depth, and copper lead for signal capture. $B$, Sample electrocardiogram output, demonstrating the appearance of an $\mathrm{H}$ wave (white arrow), which indicates tip contact with the atrioventricular node.

successful retention of $\mathrm{CHB}$, the chest was closed in layers of 4-0 vicryl, and the skin was closed with a running 5-0 nylon suture. A 60-mL syringe, attached to a chest tube, was used to evacuate the surrounding chest cavity as each animal recovered from anesthesia. Enrofloxacin $\left(5 \mathrm{mg} / \mathrm{kg}\right.$; Baytril ${ }^{\circledR}$, Bayer Healthcare) was given to prevent infection and 0.05 $\mathrm{mg} / \mathrm{kg}$ buprenorphine hydrochloride (Buprenex ${ }^{\circledR}$, Webster
Veterinary, USA) was given as needed for pain in the first 24 h. Any signs of uncontrolled distress in the animal during daily monitoring led to humane euthanasia of the animal.

\section{Results}

We defined acute heart block as $\mathrm{CHB}$ maintained for 30 
Table 1. Experimental data for atrioventricular node ablation trials in adult rabbits.

\begin{tabular}{|c|c|c|c|c|c|c|}
\hline Rabbit number & $\begin{array}{c}\text { Chemical } \\
\text { ablation agent }\end{array}$ & $\begin{array}{l}\text { Acute heart block } \\
\text { achieved? (>30 min) }\end{array}$ & $\begin{array}{l}\text { Chronic heart block } \\
\text { achieved? ( }>12 \mathrm{~h})\end{array}$ & $\begin{array}{c}\text { Survival } \\
\text { (days) }\end{array}$ & $\begin{array}{l}\text { H-wave } \\
\text { guidance }\end{array}$ & Observations \\
\hline 1 & $10 \% \mathrm{NBF}$ & yes & no & 20 & & $\begin{array}{l}\text { Animal found in distress and } \\
\text { sacrificed }\end{array}$ \\
\hline 2 & $10 \% \mathrm{NBF}$ & yes & $\mathrm{n} / \mathrm{a}$ & 0 & & $\begin{array}{l}\text { Animal died due to premature } \\
\text { extubation }\end{array}$ \\
\hline 3 & $10 \% \mathrm{NBF}$ & yes & yes & 21 & yes & $\begin{array}{l}\text { Animal found in distress and } \\
\text { sacrificed }\end{array}$ \\
\hline 4 & $10 \% \mathrm{NBF}$ & yes & $\mathrm{n} / \mathrm{a}$ & 0 & yes & $\begin{array}{l}\text { Rabbit died post-operative, likely } \\
\text { undiagnosed pneumothorax }\end{array}$ \\
\hline 5 & $10 \% \mathrm{NBF}$ & yes & yes & 37 & yes & $\begin{array}{l}\text { Animal sacrificed to examine } \\
\text { injection site }\end{array}$ \\
\hline 6 & $10 \% \mathrm{NBF}$ & yes & yes & 14 & yes & $\begin{array}{l}\text { Timed animal sacrifice to examine } \\
\text { injection site }\end{array}$ \\
\hline 7 & $10 \% \mathrm{NBF}$ & yes & yes & 10 & yes & $\begin{array}{l}\text { Timed animal sacrifice to examine } \\
\text { injection site }\end{array}$ \\
\hline 8 & $10 \% \mathrm{NBF}$ & yes & no & 10 & yes & $\begin{array}{l}\text { Timed animal sacrifice to examine } \\
\text { injection site }\end{array}$ \\
\hline
\end{tabular}

$\mathrm{H}$-wave guided injections were employed in animals 3-8. Successful long-term ablation was obtained in 4 of the 5 surviving animals. $\mathrm{NBF}=10 \%$ neutral buffered formalin.

min after injection, while chronic heart block was defined as CHB maintained for $12 \mathrm{~h}$. For long-term use as a model, the chronic condition was clearly our goal for the studies, as we noted that if the animals did not have recovery of their AV function after approximately $12 \mathrm{~h}$, recovery did not occur. As listed in Table 1, acute heart block was successful in $8 / 8$ rabbits, as confirmed by ECG, and by visual verification of continued atrial contraction with no subsequent coordinated ventricular contraction. Onset of heart block was immediate after injection of one aliquot of 0.1-0.2 mL $10 \%$ formalin into the correct plane. However, recovery of the $\mathrm{AV}$ node within $12 \mathrm{~h}$ occurred in rabbit 1 , leading us to develop the $\mathrm{H}$-wave guidance device, which was employed for the remaining animals (3-8). In these animals, we found immediate improvements in locating the desired injection site, and delivering the injectate in a manner which would create long-term $\mathrm{CHB}$ as desired.

There were two operative deaths. The first (animal 2) occurred after the animal was extubated prior to fully recovering from the anesthetic, as diaphragmatic pacing was misinterpreted as respirations. The second operative death (animal 4) had unknown etiology, but was likely secondary to an undiagnosed tension pneumothorax. There were no device-related infections.

Rabbits, which survived the procedure, were sacrificed at pre-designated time between 1 and 2 post-operative weeks for examination. Animal 5 was maintained for 37 days prior to sacrifice, as a means to judge the upper limit of animal longevity. Our larger goal of inducing chronic AV block (>12 h duration) was achieved in 4 of 5 surviving animals using the $\mathrm{H}$-wave injector guidance.
In the first two postoperative weeks, the animals tolerated their AV block well with sufficient nutritional intake and good activity, albeit with negligible weight gain. In the subsequent weeks, 2/7 rabbits developed progressive tachypnea and signs of distress. These animals were subsequently euthanized. At autopsy, both were found to have massive bilateral pleural effusions. Gross inspection of the heart, chest and abdomen of these animals revealed no other abnormality.

\section{Discussion}

These effusions were the chief pathology in the rabbits with the longest survival, and we believe that these were secondary to pacing the animal at an insufficient rate (180 bpm), thereby lowering the cardiac output. We had noted a previous report (10) of rabbits with induced $\mathrm{CHB}$ that were paced at rates as low as $140 \mathrm{bpm}$, with minimal ill effects in the short term. However, a decrease in cardiac output was also noted in that study, and the rabbits paced at $140 \mathrm{bpm}$ only survived for 8 days. A model of heart failure after creation of $\mathrm{CHB}$ with insufficient pacing has also been previously established in dogs (11). A decrease in cardiac output could be supported by the finding of our animals' weight loss although this may have also been due to stress from the surgery. Although the possibility exists that the effusions are purely reactive, it is significant that we did not encounter any large effusions in the animals that were sacrificed earlier.

We noted physiologic heart rates of 200-300 bpm prior to surgery, and the above results suggest that $180 \mathrm{bpm}$ 
allows for intermediate survival, but ultimately may be insufficient for the model. We have since reprogrammed the pacemakers to allow pacing at these higher rates. Our early preliminary experiments understandably involved some surgical deaths due to the above factors. These operative and postoperative deaths can generally be avoided with experience and understanding of the animals' specific needs, and we have seen continued improvements in animal survival after employing the revised procedures.

As described above, our future experiments will center on tissue-engineered AV node replacements. In this survival surgery scenario, heart block will be induced with our chemical method, and the animal will be maintained on a mechanical pacemaker, mimicking the clinical condition. At the time of $\mathrm{CHB}$ induction, a tissue sample will also be taken, e.g., from cardiac, skeletal, or bone marrow tissues, to provide a cell source for the tissue-engineered construct. This scaffold can be grown in vitro until the cell density, alignment, and differentiation state are sufficient for reimplantation. In this model, the original pacemaker may be turned on or off to test whether the engineered implant can independently conduct its signal. Our injector technique will again find utility, prior to animal sacrifice, by identifying and selectively ablating the implanted construct. If the implanted tissue is successful in creating an electrical connection between the atrium and the ventricle, the heart rate should once again decrease after this graft is ablated.

\section{References}

1. Weindling SN, Saul JP, Gamble WJ, Mayer JE, Wessel D, Walsh EP. Duration of complete atrioventricular block after congenital heart disease surgery. Am J Cardiol 1998; 82: 525-527.

2. Choi YH, Stamm C, Hammer PE, Kwaku KF, Marler JJ, Friehs I, et al. Cardiac conduction through engineered tissue. Am J Pathol 2006; 169: 72-85.

3. Boucher M, Duchene-Marullaz P. Methods for producing experimental complete atrioventricular block in dogs. $J$ Pharmacol Methods 1985; 13: 95-107.

4. Erlanger J, Blackman JR. Further studies in the physiology of heart block in mammals. Chronic auriculo-ventricular heart-block in the dog. Heart 1909; 1: 177.

5. Guzman SV, Deleon AC Jr, West JW, Bellet S. Cardiac effects of isoproterenol, norepinephrine and epinephrine in complete A-V heart block during experimental acidosis and hyperkalemia. Circ Res 1959; 7: 666-672.

6. Karpawich PP, Bharati S, Roskamp JO, Lev M. Selective
In summary, we have described an improved method to facilitate ablation of the AV node in the rabbit model, through external confirmation of the AV node location. Our injection device, with an angled injection tip, fixed injection distance, and $\mathrm{H}$-wave readout, provides both physical and electrical guidance in reaching the site of interest. These features reduce unnecessary damage to the surrounding heart tissue, and decrease the amount of formalin needed to create $\mathrm{CHB}$. While acute AV block could be quickly induced with NBF injections in all animals, our ultimate goal of chronic AV block was most successfully attained through the use of this improved injection device. This in vivo model provides a necessary resource for the investigator, to test new therapies in the restoration of AV conduction.

\section{Acknowledgments}

We thank Dr. J. Hernandez and the RSF staff at Children's Memorial Research Center for rabbit anesthesia, airway management and excellent animal care. All pacemaking equipment was generously donated by Medtronic (Minneapolis, MN, USA). D.A. Harrington gratefully acknowledges support from the Dr. Ralph and Marian C. Falk Medical Research Trust. We acknowledge financial support by Children's Memorial Hospital, Children's Memorial Research Center. transepicardial ablation in the immature canine myocardium. A more precise method. $J$ Thorac Cardiovasc Surg 1989; 97 : 893-899.

7. Williams J, Lambert E. Production of heart block in dogs without thoracotomy. Fed Proc 1964; 23.

8. Steiner C, Kovalik AT. A simple technique for production of chronic complete heart block in dogs. J Appl Physiol 1968; 25: 631-632.

9. Lee RJ, Sievers RE, Gallinghouse GJ, Ursell PC. Development of a model of complete heart block in rats. $J$ Appl Physiol 1998; 85: 758-763.

10. Suto F, Cahill SA, Wilson GJ, Hamilton RM, Greenwald I, Gross GJ. A novel rabbit model of variably compensated complete heart block. J Appl Physiol 2002; 92: 1199-1204.

11. Starzl TE, Gaertner RA. Chronic heart block in dogs; a method for producing experimental heart failure. Circulation 1955; 12: 259-270. 